\title{
Relationship between global public spaces on campus and the effects of dynamic activities and static activities
}

\author{
Yu-Peng Xu, Fang Wu and Sheng $\mathrm{Li}$ \\ Department of Architecture, Zhejiang University City College, \\ Hangzhou, China \\ E-mail: duncanchn@126.com \\ Corresponding author: elcroquis@163.com
}

\begin{abstract}
An exploratory study of combinations among environment behavior science, space syntax and interactive activities on campus is presented. To answer the reason why the public spaces on campus could not be used effectively as expected, the study focuses on the potential relationship between spatial configurations and interactions among associations in public spaces, two ways included: observations of activities and analysis of spatial configurations using space syntax methods. Based on stream-centered Network analysis methods, the data in the study shows the correlation between real activities and theoretic features of spatial configuration. As a result, it is proved that the difference in vitality of campus space origins from the difference in spatial configurations. Besides, the spatial shelter, vehicles occupation and visual fields of one space appear to make critical roles in vitality of public spaces.
\end{abstract}

Keywords: Public spaces on campus; Spatial configuration; Interactions; Sustainability

\section{Introduction}

\subsection{Context}

Since the 1990s, campuses with giant scales or loose layouts have been emerging in large numbers. The distant intervals with extremely wide roads make most buildings separated by huge outdoor space, resulting in the lack of continuous pedestrian network and the dependence on vehicles like automobiles and bicycles. Speaking to the developing focus of those campuses, most colleges are mainly developing in three aspects: improving qualifications of teachers and students, providing financial support on diverse academies and designing physical environment. While the design of physical environment originally aims to improve students' learning and discussing enthusiasm in those designed spaces, these so-called 'public spaces' could not be effectively used due to the deficient consideration about the relationship between spatial configurations and social interactions. 
With the introductory of sustained campus, the planning and renovating focus is adjusted to the improvement of public spaces on campus, to increase the chance that people encounter each other and people do some learning in public areas. Thus it means something for the goal if students can study spontaneously under education system centering on teaching rather than students 'learning.

\subsection{Research purpose}

The study is to explain why the vitality of public spaces in varied spots differs from each other, analyzing the correlation between spatial vitality and spatial configuration and therefore expelling the potential factors.

\subsection{Literature review}

During these years, some internal research on public spaces on campus have been carried out. Xiao-Ling Dai [1], comes up with some valuable on-site methods of recording dynamic and static activities in urban design. Song Wang[2], combines facility network and place network to describe accessibility and spatial characters in the walk able community.

Some research abroad have explained the spatial configuration's influence on the transmission of knowledge and innovation. Tom Allen[3],in studying communication and innovation in engineering found that people's random encounter and co-presence in space might be one key point in transmission of knowledge and innovation. Granovetter[4], makes an important distinction between 'strong' and 'weak tie 'between people in social networks. He also found another strong role of spatial configuration in generating the weak networks, which can ultimately lead to the socialization. Hillier and Penn[5] distinguish two types of knowledge and point out that if the social knowledge "we think with" were absent, the scientific knowledge would tend to happen. Greene $\mathrm{M}$ and Penn A[6] proves that global integration better explains the relations between students and academics of the same campus and local integration better explains the relations between students and academics of other campuses.

To sum up, the mechanism where spatial configuration impacts innovation and socialization has made some basic achievements. However, the study of this field in China is still in the beginning stage. This study made an attempt to synthetically consider the theory of environment behavior, psychology and spatial configuration into the vitality of public spaces on the campus. 


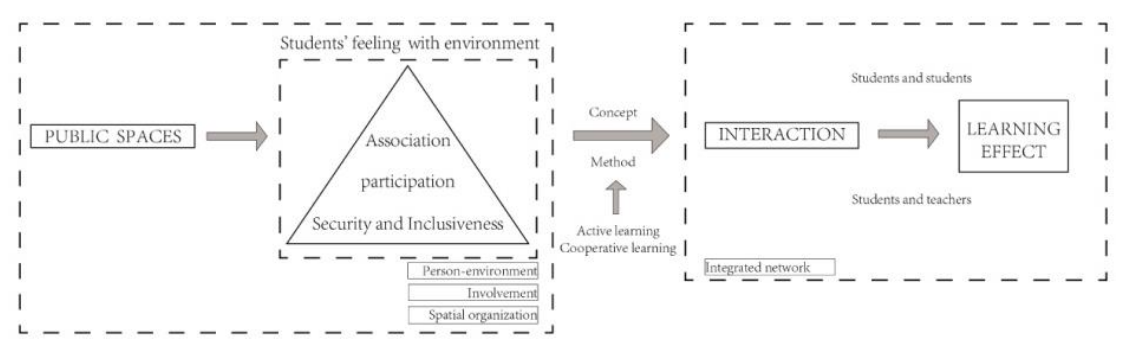

Fig. 1. The acting path of from public space to learning effect

\section{Methodological Procedures}

The methods consists of two major parts: the record of activities of participants on campus and the analysis of spatial configuration. The spatial configuration of the whole campus and public spaces can be shown in space syntax to clarify the theoretical character of space; the activities of participants can be obtained from observations, where every data represents the real character of certain points on the campus. Hence conclusions can be drawn through correlation.

\subsection{Observations of participants' activities}

\subsubsection{Observations of dynamic activities}

Counting method of generalization is used in observations of dynamic activities. The plane of the campus is divided into four areas(from a to d), which respectively presented four main areas of complex. Each area contains nine observation points, which maximized the ranges covering most representative places and minimized the time cost when walking among points.

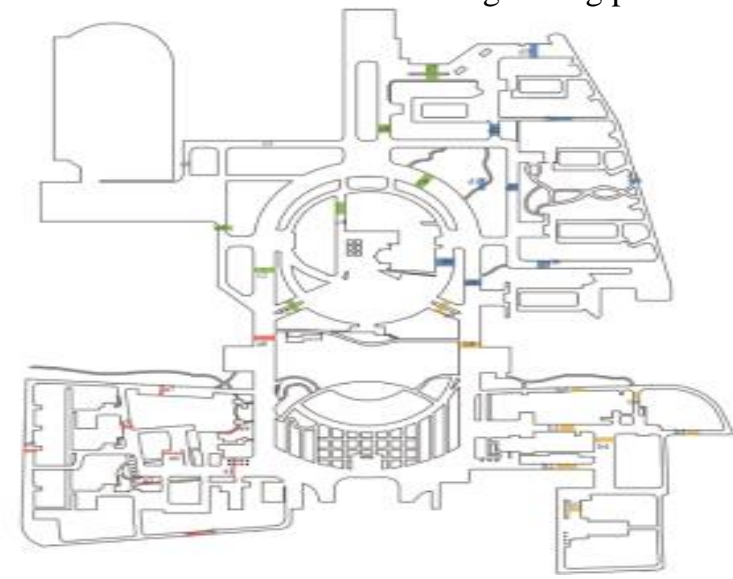

Fig. 2. The dispersion of observation points.

Taking the difference between weekdays and weekends, observations of 
such kind of activities were conducted twice, contained six periods of time to obtain the average flow of people and vehicles on weekdays and weekends.

\subsubsection{Observations of static activities}

Observations of static activities are used to describe the activities of participants in public spaces and to measure the vitality of certain spaces. The major public spaces disperse in twelve spots, five indoors and seven outdoors. Since the activities are often related to academic discussions and self-study, most public spaces are near the academic buildings to offer great convenience to students.

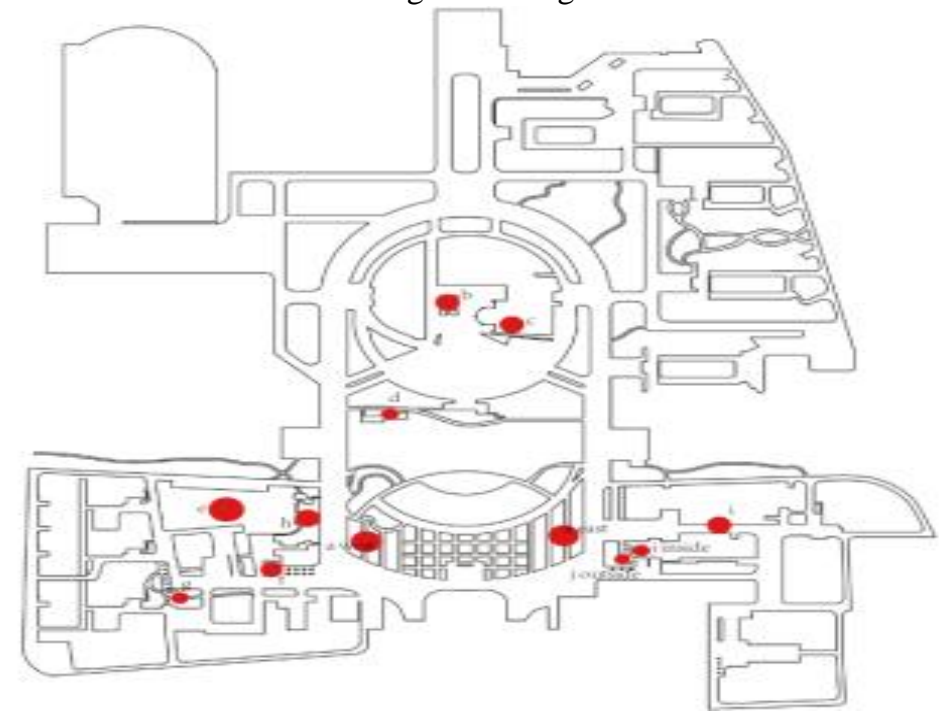

Fig. 3. The dispersion of public spaces: $a$ - the western square; a east - the eastern square; $b$ - the entrance square of the library; c — the library's hall; $\mathrm{d}$ - the lakeside; e — the Science No. 4' s hall; $\mathrm{f}$ - the bar; g- the benches near Science No. 4; $\mathrm{h}$ — the benches near Liberal Art No. 1; $\mathrm{j}$ insidethe bar in Liberal Art No. 2; j outside - the benches outside.

Detailed information is recorded how many people gathered, which form they acted in, standing or sitting, discussing or self-learning. The observation was accomplished on June 12, 2016. Thinking high temperature affects people's activities, the study extracted three periods of time, 9 am to $10 \mathrm{pm}, 4 \mathrm{pm}$ to $5 \mathrm{pm}$ and $6 \mathrm{pm}$ to $7 \mathrm{pm}$ to record accumulated activities happening in public spaces.

\subsection{Spatial configuration on campus}

\subsubsection{Spatial configuration of the whole campus}

The convex space is defined with 'everything see everything', whereas the space on campus can be interrupted by many crossings, even if some points belong to 
the same axis, they might have distinct characters. In segment models, it can be explained clearly, so the study is mainly based on segment models.

\subsubsection{Spatial configuration of public spaces}

The spatial network is based on the ground floor network of the whole campus. To describe space covered with many lines or not covered by outdoor lines, one attempt is made through identify features of space with some adjacent lines. If the space has one line, the value is equal with the line's value; if the space has several lines, the value is mid-value or average value of those lines; if the space is indoor, the value is taken as the value of lines in the space near the entrance.

\section{Result}

\subsection{Situations and features of dynamic and static activities}

Through recording the dynamic activities, the point ${ }^{\circ}$ b8' is the most highly trafficked spot, because this bridge connects two important areas: complex of dormitories and complex of teaching academic buildings. However, the result shows some zero flow like point' ${ }^{\prime} 6$ ', point ' $\mathrm{d} 5$ ' and point ' $\mathrm{d} 6$ ', which are near the edge of the campus or have no building around.

According to the observation, it seems that point ' c' and point' a east' have abundant activities no matter in learning or in discussing: one is indoor and the other is outdoor. However, public spaces in point' $h$ ' and point ' $i$ ' are wasted for no one would like to stay there. The situation that they have different vitality may be due to the shelter and vehicles' occupation, which needs more evidence.

\subsection{Analysis of spatial configurations}

\subsubsection{Spatial configurations of the whole campus}

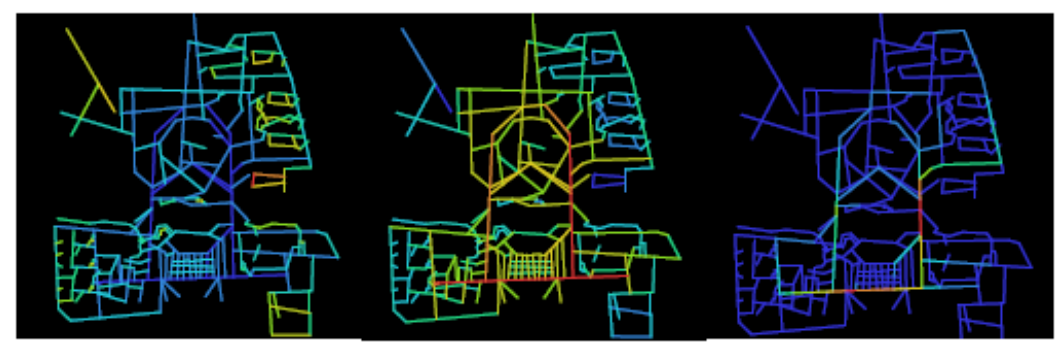

Fig. 4. T1024 Total Depth, T1024 Integration, T1024 Choice(Segment Length Wgt)

It is shown that the higher integration means the lower total depth, and in the choice model there are only several bright lines with high T1024 choice. 


\subsubsection{Spatial configurations of public spaces}

It is recorded that the mid-value and average value of choice vary much widely than and those of integration and total depth of public spaces.

\subsection{Correlation activities and spatial configurations}

\subsubsection{Correlation dynamic activities and spatial configurations}

Compared with the theoretical characters shown in space syntax, the record of dynamic activities suggest the real character of people walking on the campus. With the assistance of SPSS, the correlation among varied data can be shown clearly in one table.

Table 1. This is the correlation between dynamic activities and spatial configurations on weekdays.

\begin{tabular}{|c|c|c|c|c|c|c|c|c|c|c|c|}
\hline & & $\begin{array}{l}\text { Tl024 } \\
\text { Choice }\end{array}$ & \begin{tabular}{|c|} 
Integratio \\
a
\end{tabular} & $\begin{array}{l}\text { Total } \\
\text { Depth }\end{array}$ & $\begin{array}{c}\text { Nale } \\
\text { student }\end{array}$ & $\begin{array}{l}\text { Female } \\
\text { student }\end{array}$ & teacher & motor & non-motor & student & All peop \\
\hline \multirow{3}{*}{$\begin{array}{l}\text { Til024 } \\
\text { Choice }\end{array}$} & Pearson & & $.695^{\prime \prime}$ & $.602 "$ & $.508^{\prime \prime}$ & $.594^{\prime \prime}$ & .006 & $.624 "$ & $.398^{\circ}$ & $.637^{\prime \prime}$ & $.637^{4}$ \\
\hline & Significan & & .000 & .000 & .002 & .000 & .973 & .000 & .016 & .000 & 0 \\
\hline & & 36 & 35 & 35 & 36 & 36 & 36 & 36 & 36 & 36 & \\
\hline \multirow[t]{3}{*}{ notor } & Pearson & $.624^{\prime \prime}$ & $.546^{\prime \prime}$ & $\cdot .417^{\prime}$ & $.822^{\prime \prime}$ & $.589^{\circ "}$ & .122 & 1 & $.741^{\prime \prime}$ & $.722^{\prime \prime}$ & .727 \\
\hline & Significan & .000 & .001 & .013 & .000 & .000 & .478 & & .000 & .000 & .00 \\
\hline & $\begin{array}{l}\mathrm{ce} \\
\mathrm{N}\end{array}$ & 36 & 35 & 35 & 36 & 36 & 36 & 36 & 36 & 36 & \\
\hline
\end{tabular}

Theoretically, T1024 choice suggests the times that one element appear in the shortest topological distance, which means the potential ability to attract one to cross. On campus, it shows the potential to attract people to cross the path.

However, in Table 1, and Figures 5, T1024 choice do not show a strong correlation between choice and dynamic activities of students; on the contrary, the flow of motors seems strongly related to choice, which leads to an assumption whether the presence of automobiles weakens the correlation between choice and dynamic activities of students. 

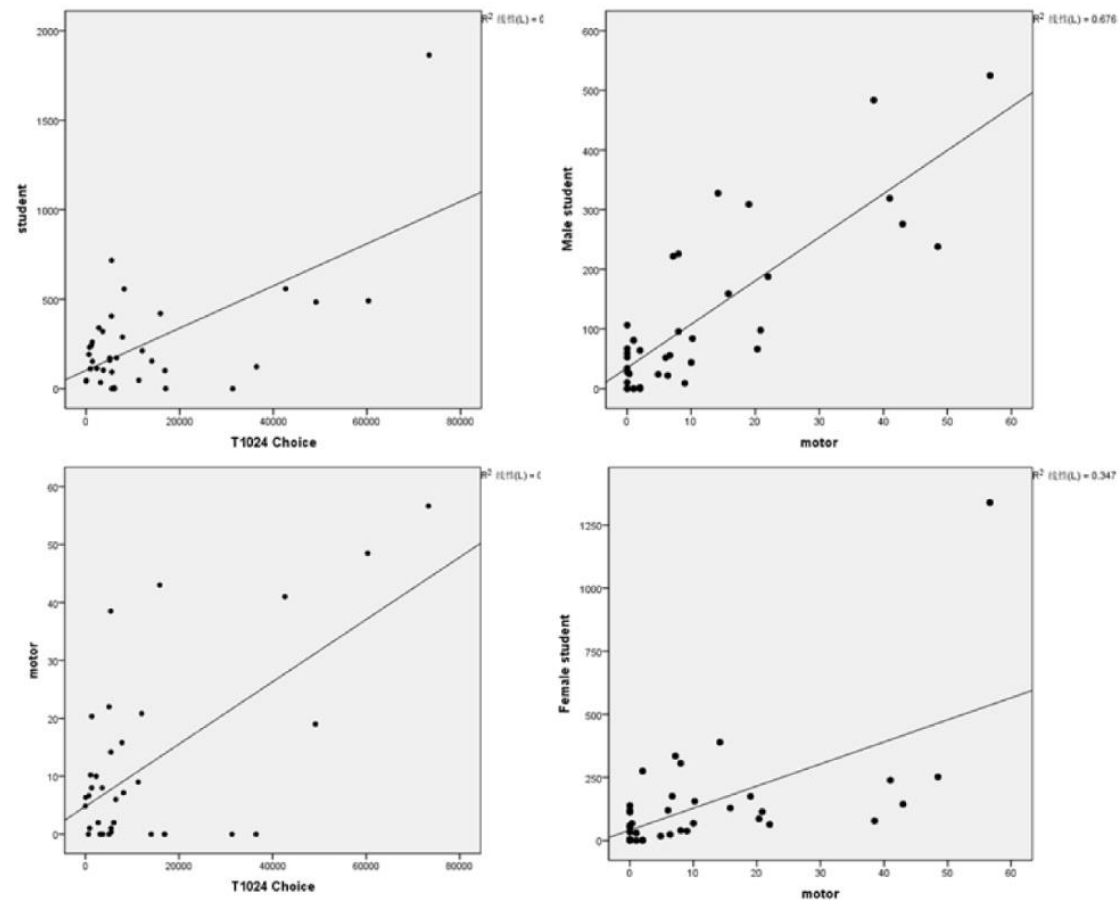

Fig. 5. Correlations of choice, motor and others on weekdays.

To analyze the changes of choice on weekdays and on weekends, the study uses SPPS on data of weekends as well. In Table 3 and other figures, there is still no strong correlation between choice and dynamic activities of students.

Besides, comparing two tables, a huge difference on the correlation between male students, female students and choice exists. It is possible that although the motor flows of weekends and weekdays are similar, the drivers may be different groups. On weekends, since students are more likely to go out, the motors are more likely to be driven by students' family and themselves instead of teachers and staff. So psychologically the weak correlation between female students and motor on weekdays can attack some blame to the risk caused by motors. And on weekends, if students were divers, there would be little risk; if students were walkers, they could be at ease because they are in resting days. 
Table 2. This is the correlation between dynamic activities and spatial configurations on weekends

\begin{tabular}{|c|c|c|c|c|c|c|c|c|}
\hline & \begin{tabular}{|c|} 
T1024 \\
Choice(avg \\
\end{tabular} & \begin{tabular}{|c|}
$\mathrm{T} 1024$ \\
Integratio \\
$\mathrm{n}($ avg $)$ \\
\end{tabular} & \begin{tabular}{|c|} 
T1024 \\
Total \\
Depth(avg) \\
\end{tabular} & \begin{tabular}{|c|}
$\mathrm{T} 1024$ \\
Choice(mid \\
\end{tabular} & \begin{tabular}{|c|} 
T1024 \\
Integratio \\
n(mid)
\end{tabular} & $\begin{array}{c}\text { T1024 } \\
\text { Total } \\
\text { Depth(mid) } \\
\end{array}$ & $\begin{array}{c}\text { discussing } \\
\text { people }\end{array}$ & \begin{tabular}{|c|}
$\begin{array}{c}\text { luding } \\
\text { discussing } \\
\text { ) }\end{array}$ \\
\end{tabular} \\
\hline $\begin{array}{ll}\text { T1024 } & \text { Pearson } \\
\text { Integratio } & \text { Significan } \\
\text { n(mid) } & \text { ce } \\
& \text { N }\end{array}$ & $\begin{array}{r}.530 \\
.076 \\
12\end{array}$ & $\begin{array}{r}.975^{\circ 7} \\
.000 \\
12\end{array}$ & $\begin{array}{r}-.980^{\circ \prime} \\
.000 \\
12\end{array}$ & $\begin{array}{r}.447 \\
.145 \\
12\end{array}$ & 12 & $\begin{array}{r}-.994^{2 "} \\
.000 \\
12\end{array}$ & $\begin{array}{l}.632^{\circ} \\
.027\end{array}$ & $\begin{array}{l}.606 \\
.037\end{array}$ \\
\hline
\end{tabular}

\subsubsection{Correlation static activities and spatial configurations}

According to the SPPS analysis result, the mid-value of integration in can segment model is related to the static activities in some degree. So the higher the integration of some space is, the higher the chance of people staying and learning in this space.

Judging from Figure 3., Figure 4, point' a west 'and' j outside' are both next to the most integrated lines, but the vitality of point' a west' is much higher than point' $\mathrm{j}$ outside', where the shelter assumption cannot be applied to these. Visual fields might explain the phenomenon in that point' a west' being on the square offers people a wide sight and control on more space, whereas the other one is surrounded by shrubs, which is too crowded to use.

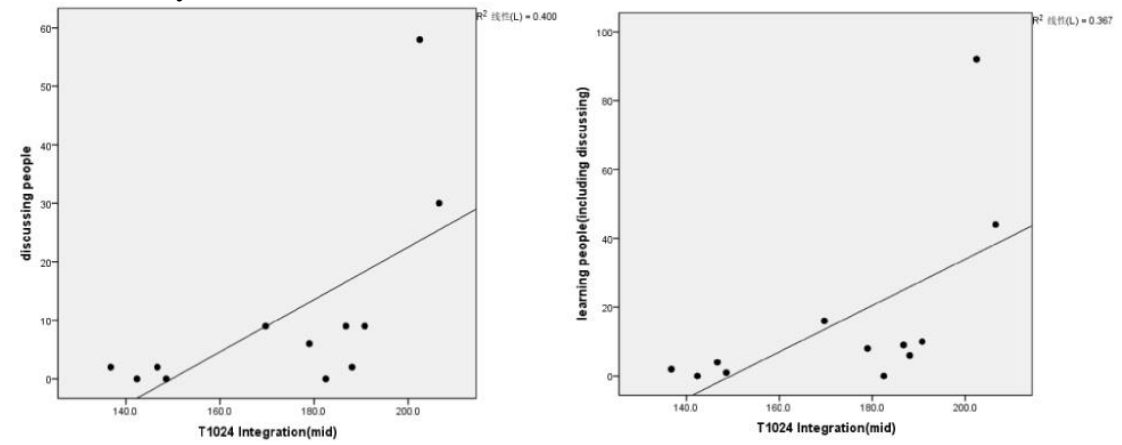

Fig. 6. Correlations between integration and others on weekends.

\section{Discussion and future}

The difference among campus public spaces origins from spatial configuration: the vitality is slightly related to choice, the moving attribute cannot explain people's gathering or learning; but the integration of spaces can affect people's activities in these space. Of course, shelter and visual field are also the standard for people to use. No matter buildings or trees, shelter provides people with safety and comfort. A good visual field gives people strong control on stuff nearby. Besides, motors in the campus affect students' activities a lot due to the safety problem and noises, which can be directly perceived by female students. 
There still exists some error in the whole study, for instance, the inaccuracy of the observations due to the contingency of people's going out; the method using mid-value or average value to describe complex space; and the timeliness of maps because of the constant construction on campus. Obviously some new shortcuts can affect students' moving path and the vitality local public spaces.

In addition, it is potential to combine visual integration with vitality, completing the rules impacting students' activities. While the study relies on extensive analysis, motor problem has not been separated. The future study can try to explain motors' impacts on participants' activities, comparing walking and driving segment models with real activities for sustained layouts of campuses.

\section{References}

1. Xiao-Ling Dai, On-site Investigation Methodology in Urban design-From the perspective of Environment-behavior Studies, Tongji University, 2010

2. Song Wang, Axial Map Analysis of Facility Network and Place Network in Walkable Community, Architectural Practice, 2013: 1003-739 X

3. Allen, T. (1977) Managing the Flow of Technology. Cambridge.

4. Granovetter, M. (1982) The strength of weak ties. In P. V. Marsden and N. Lin (Eds.). Social Structure and Network Analysis. Beverly Hills: Sage Publications Inc.

5. Hillier, B. and Penn, A. (1991) Visible colleges: structure and randomness in the place of discovery. Science, 1991, 4(1):23-50

6. Greene M, Penn A. Socio-spatial Analysis of Four University Campuses: The Implications of Spatial Configuration on Creation and Transmission of Knowledge [C]. Seoul: Space Syntax Seoul Organizing Committee. Space Syntax First International Symposium, 1997: 13.1-13.16. 